\title{
ТЕАТР КАК «ОБРАЗ ЖИЗНИ» ЧЕЛОВЕКА С ИНВАЛИДНОСТЬЮ: АНТРОПОЛОГИЧЕСКИЕ НАБЛЮДЕНИЯ
}

\begin{abstract}
В статье на основании пилотного исследования методом кейс стади прослеживаются связи инвалидности с искусством: какой путь проходит человек с инвалидностью, стремясь к театральному творчеству? Ответ на этот вопрос строится через попьтку рассмотреть жизнь человека с инвалидностью как своеобразную социальную драму, и увидеть то, какие трансформации происходят при взаимодействии реальньх жизней с реальным театром. Контекст привычного нам театра смещзется от формата вылуманных персонажей и их историй, упакованных в рамки воображаемого мира одного автора, в сторону персонажей, со-творящих художественный проект реалистичными деталями своих индивидуальных жизненных нарративов. Это становится возможным благодаря феномену сочииального театра. Он, как и его форма - инклюзивный театр, вмещзает в себя, помимо эстетической составляющей, иную иерархию - горизонтальную, где каждый участник - творец на равных, имеющий свои зоны ответственности. Образ инклюзивного театра раскрывается на конкретном примере крупного российского проекта «Инклюзион», работающего в семи городах России. На Новосибирском кейсе этой сети театральных икол иллюстрируется, какие ценности позиционируются артистами с инвалидностью как те, что делают жизнь человека «наполненной», несмотря на «ограниченные возможности».
\end{abstract}

Ключевые слова: исследования инвалидности, инвалидность, соииальный театр, инклюзия, инклюзивное искусство, люди с ограниченныли возможностями здоровья, инклюзивньй театр

Ссылка при цитировании: Торлопова Л.А. Театр как «образ жизни» человека с инвалидностью: антропологические наблюдения // Вестник антропологии, 2021. № 1 (53). С. 50-60.

Данная статья является результатом пилотного исследования методом кейс стади, посвященного феномену инклюзивного театра. Рассматриваются ценностные показатели такого понятия как «полноценная» жизнь и пути, которыми она достигается в ситуации определенных ограничений здоровья и особенностей жизненной ситуации человека. Не в противовес, а в дополнение к «ограничениям

Торлопова Любовь Андреевна - научный сотрудник НОЦ «Социально-политические исследования технологий», Томский государственный университет (634050 Томск, пр. Ленина, 36) Эл. почта: lyubovtorlopova@gmail.com. Orcid.org/0000-0003-2809-9965

* Статья подготовлена при финансовой поддержке Российского фонда фундаментальных исследований в рамках проекта № 20-09-00063 «Инвалидность как социокультурный феномен на постсоветском пространстве: социально-антропологический и кросс-культурный анализ» 
здоровья», «ограниченным возможностям», «трудностям коммуникации», «ограничениям в передвижении» и т.п. выделяется пространство для таких категорий как «наполненная жизнь», «альтернативные коммуникации, способы передвижения» и т.д. Делается попытка рассмотреть жизнь человека с инвалидностью как своеобразную социальную драму, раскрывающую трансформации жизни при взаимодействии с реальным театром.

В своем исследовании я пыталась ответить на следующие вопросы: 1) как трансформируется жизнь человека с инвалидностью, когда в ней возникает новый объект - театр? Какие метаморфозы в такой ситуации происходят в сознании (восприятии жизни) у человека? 2) Как меняется понятие и феномен театра в связи с появлением инклюзии? Что такое социальный театр и чем он отличается от «классического»? 3) О каких ценностных ориентирах идет речь, когда говорят о «полноценной жизни» при условиях «ограничений здоровья»?

\section{Материалы и методы}

С ноября 2019 по март 2020 гг. проводились практики включенного наблюдения в рамках спектаклей и иных открытых мероприятий_«Инклюзиона» в Новосибирске (репетиции, открытые лекции для «студийцев»; посещение спектаклей, в том числе в интерактивном формате). С апреля по июнь 2020 г. проделана работа по поиску, отбору, анализу и расшифровке публичных видеоматериалов. В июне-июле 2020 г. были проведены пробные интервью с участниками проекта. Включенное наблюдение происходило в театральной студии «Инклюзион» в Новосибирске на спектаклях «Несильный»; «Юшка»; «Про Свет Лень Я»; «Unреальность» (репертуар студии не ограничен только этими спектаклями), а также на иных «открытых» мероприятиях: площадке «Театр маркет» (ярмарка для творцов рукоделия и артистов, желающих выступить в рамках открытого творческого пространства) как проекте интеграции, публичной репетиции театральной студии «Инклюзион» и тематической лекции. Значимый корпус источников в этом пробном исследовании занимают записирасшифровки видеоматериалов, взятых из открытого доступа в сети Интернет (региональные и федеральные СМИ, частные записи интервью самопрезентации людей с инвалидностью или организаторов творческих объединений).

Театральные постановки школ являются творческим уникальным продуктом конкретных коллективов, которые под руководством их режиссеров и педагогов в процессе тренингов и занятий занимаются со-творчеством спектакля, на основании собственного опыта. Поскольку студенты не являются профессиональными актерами, а качество спектаклей важно для школ, то для подлинности игры в спектакле подбираются темы, вызывающие глубокое личное сопереживание учеников. За счет этого постановки, их события и персонажи получаются «живыми», «эмоциональными», «настоящими». Вслед за Хейзинга (Хейзинга 1997) и его последователями, я понимаю жизненную траекторию человека как театр, в том числе и жизненный путь человека с инвалидностью. При этом, согласно данным Всемирной организации здравоохранения (ВО3), «более одного миллиарда человек в мире имеют какую-либо форму инвалидности» (Всемирная организация здравоохранения 2011), это означает, что приблизительно один из восьми человек на планете столкнулся с феноменом инвалидности лицом к лицу. 


\section{Феномен и понятие социального театра}

Зачастую искусство, и театр в частности, помогает обратить внимание общества на трудные, порой неприятные, или объемные, масштабные, выходящие за пределы повседневной жизни и ее проблематики темы. Проблематика социального театра проникают в различные сферы и слои общества. Например, проект социального театра «Кактус» (Jimenez-Aceituno, Medland and others 2016: 281-297) в Испании посвящен экологической теме. А в работе Августо Боэла «Эстетика угнетенных» описан опыт «театра в тюрьме» (Boal 2006: 103).

Что касается России, то здесь много внимания направлено профессиональным творческим сообществом на человеческие трудности разных уязвимых социальных групп. «Социальный театр» представляет собой спектакли на социально значимые, острые, «неудобные» темы. Но всё чаще это театр, который включает в активное участие тех, кого эти острые темы касаются, в каком-то смысле предлагая им сыграть свою жизнь как роль на сцене. «Постановки с участием людей с ментальными особенностями, незрячих или слепоглухих актеров, подростков из детских домов, заключенных или пенсионеров и пр. перестали быть лишь арт-терапией для “особых” актеров - теперь они становятся полноценными театральными спектаклями, имеющими художественную и социальную ценность» (видео «Что такое “социальный театр”»). Конкретные личности приобретают легальный статус своего проявления в социокультурном пространстве через бережную интеграцию. Это позволяет не только аудитории, а до этого участникам труппы извне уязвимой социальной группы, меняться и менять свое восприятие ситуации, но также позволяет и представителям уязвимой группы меняться, будучи включенными в иное сообщество - сообщество со-творцов искусства. Они перестают быть просто и только представителями «иного» мира, снижается уровень их аутсайдерской позиции, а вместе с тем начинают теряться жесткие границы и размываться стигматизация. Некоторые авторы предпочитают понятие «особенный театр», для них значим акцент на «особенностях развития» каждого артиста. “Особенности развития - это не просто ограничения, а определенные возможности внутри определенных ограничений. И вот с этими возможностями мы и работаем, когда занимаемся творчеством (Афонин 2018: 13. Курсив мой - Л.А.). Социальный, горизонтальный театр - про «Все равны. Но у каждого своя зона ответственности» (Пархомовская 2019: видео).

Трансформационныепроцессы в таком театре могут иметь разные направления. Не только режиссер-задумщик или сценарист влияют на актеров, которые в дальнейшем повлияют на зрителя, что иллюстрирует линейность такой трансформации. Но также и актеры через рассказывание своих жизненных историй могут (пере)создавать канву сюжета или нестандартный формат общения, как в случае, когда место встречи участников создает новые формы общения и со зрителем, ведь «социальный театр - не по рецепту» (Пархомовская 2019). Его постановка в качестве одной из своих творческих предпосылок не имеет какой-то специфической заготовленной драматургической схемы, скорее, она рождается в процессе совместной творческой работы всех участников, о чем подробнее будет рассказано далее.

Для Афонина «особый театр» «ставит своей целью создание художественного произведения, а его воздействие на социум является дополнительным, вторичным эффектом» (Афонин 2018: 8). Московский проект «Театр Простодушных», созданный в декабре 1999 г. сообществом родителей людей с синдромом Дауна и 
режиссером Игорем Неупокоевым видится как «творческая мастерская, некоммерческий драматический театр» (История. Театр Простодушных). Для режиссера в данном случае первостепенно творчество и художественный продукт, а социализация артистов - следствие (Маркина 2012: 7965-7974).

\section{Инклюзион}

Инклюзивный театр на сегодняшний день разнообразно представлен в России. «Инклюзион» - некоммерческая

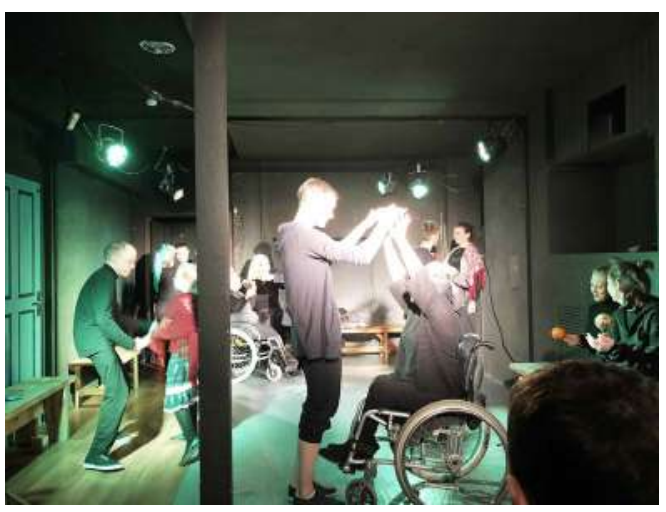

Рис. 1. Спектакль “Юшка”, 2020, Новосибирск, (фото: Л.А.Торлоповой) организация, основанная в г. Москва. Несмотря на свою юность (открылась в 2017 г.), это уже целая сеть театральных школ, которые находятся в семи городах: Москве, Санкт-Петербурге, Екатеринбурге, Казани, Калининграде, Новосибирске и Орске. Проект, созданный в рамках работы Фонда поддержки слепоглухих «Со-единение», видит своей миссией развитие инклюзивного театра в России (Инклюзион/О центре). Центр реализации творческих проектов «Инклюзион» подразделяется на два направления: театральные школы и театральные труппы, играющие в спектаклях. Школы созданы благодаря проведению в городах театральных лабораторий или обучению их организаторов в столицах. «Студийцы» проходят месяцы обучения, прежде чем начинают играть в спектаклях. Зачастую посещаемые ими занятия включают в себя такие дисциплины как актерское мастерство, пластика, сценическая речь, звучание (Сборник 2020: 22, 24, 28, 29, 38, 39, 43). В основном занятия занимают несколько часов, пару дней в неделю. Организаторами становятся режиссеры, которым откликается тема инклюзивности, или творчески ориентированные люди с инвалидностью. Необходимым условием для открытия школы является партнерство с местными театрами, в разных случаях - с государственными или частными, поддержка театральных организаций. Этот проект является современным уникальным феноменом инклюзивного театра, поскольку ему удалось, зародившись в Москве, распространиться за пределы европейской части России, и несмотря на разбросанность в регионах, сохранить и поддерживать высокий уровень творчества. Спектакли создаются постепенно: при открытии конкретной школы студенты активно задействуются в выборе темы и содержании постановки.

Инклюзивные театральные коллективы создают художественные проекты, раскрывают потенциал учеников своих школ, развивают инклюзивное театральное образование, формируют пространства для взаимообмена творчества, знакомят широкую аудиторию с инклюзивным искусством, чем создают потенциал для трансформации восприятия инвалидности.

История создания и развития каждого филиала Инклюзиона уникальна, в «фактуре» каждой из школ и процессе их создания нет унифицированности. Они были созданы и развиваются под влиянием локальной ситуации: «в зависимости от состава команды, которая стояла у их истоков, и контекстов, в которых они существуют» (Сборник 2020: 14). Так, Новосибирский «Инклюзион», ученики которого имеют 


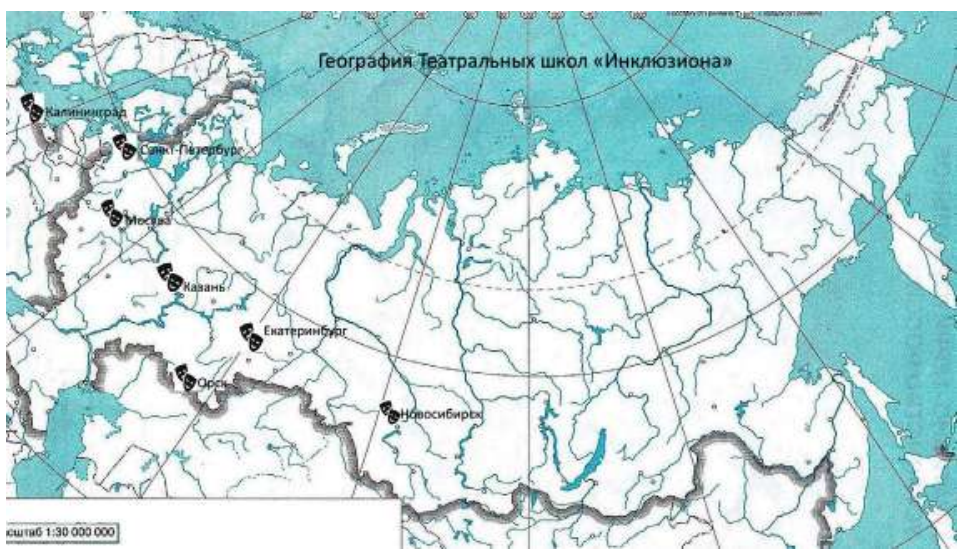

Рис. 2. Карта школ "Инклюзион”" разные инвалидности, представляет собой энергичное пространство с высокими темпами активности, «где практически каждые два месяца выпускают новый спектакль, где получают приглашения на престижные театральные фестивали, где кипит жизнь» (Сборник 2020: 14). Практически противоположно, в плане событийной интен-

сивности и разнообразия, но с не меньшей ценностью разворачивается пространство театральной школы в Санкт-Петербурге, «где большая часть студентов - это слепоглухие люди старшего возраста. И главная ценность этой школы - это очень внимательное и бережное отношение к каждому участнику и одновременно системный подход» (Сборник 2020: 19, Медюх Т., Директор по развитию).

Некоторые спектакли уже идут в регулярном репертуаре, например, такие есть в Москве и Новосибирске. Уникальным случаем является калининградская театральная школа «Инклюзиона», где собралось целых две обучающих детских группы учеников с нарушением слуха (хотя «нормотипичные» дети также в них обучаются). По словам педагога школы, актрисы Калининградского областного драматического театра М. Юнганс: «Мыстараемся объяснить детям, что вообще такое театр, стараемся проводить занятия так, чтобы не задавить их индивидуальность, дать возможность быть самими собой. Взять их сильные стороны и “подсветить”, сделать видимыми» (Сборник 2020: 60).

\section{Процесс «производства» спектакля в социальном театре}

С первой крупной московской лаборатории «Инклюзиона» утвердилась высокая планка качества художественного продукта. Каждая театральная школа открывается, создавая коллаборацию с театрами (как государственными, так и частными) и творческими объединениями или независимыми режиссерами. В результате той первой лаборатории в 2015 г. был создан спектакль на основе реальных историй актеров - «Прикасаемые». Под влиянием профессиональных педагогов и «зрячеслышащих» коллег-актеров слепоглухие артисты стали демонстрировать более высокий уровень активности, скоординированности, улучшения «зоны внимания», «то есть у них развились те качества, которые присущи профессиональным артистам» (Сборник 2020: 21).

В Санкт-Петербургской театральной школе, созданной в 2017 г., преобладают незрячие актеры. Стабильный коллектив из педагогов и участников в ней складывал-

\footnotetext{
${ }^{1}$ Комментарий к Рис. 2: Шаблон контурной карты взят на просторах Интернета. Отметки городов и указания о существовании там театральных школ “Инклюзиона” сделаны автором.
} 
ся в течение года. Опыт этой школы показывает, насколько в социальном театре значимы реальные условия создания спектакля и истории его участников. Декорации, образ, сюжетная линия спектакля «Ночи Холстомера» связаны с коммунальнобытовыми условиями, социальными и личностными рамками, и теми процессами, которые естественно разворачивались в группе: знакомства друг с другом и творчеством внутри и вокруг себя. По словам режиссера спектакля А. Савчука, «Мы сидели в кругу [в маленьком зале Библиотеки “для слепых и слабовидящих”, где проходили встречи-репетиции] (так в спектакле тоже появился круг) и обсуждали разные темы... Мы наговаривали и копили истории, из которых должен был собраться спектакль» (Сборник 2020: 35).

Зачастую спектакли являются творческими коллективными интерпретациями известных авторов и их произведений: В. Шекспира (спектакль «ШекспириЯ»), Л.Н. Толстого - «Ночи Холстомера», А.Н. Островского - «Гроза - среда обитания», Н.В. Гоголя - «Совершенно невероятное событие. Женитьба», спектакль по сказкам А.С. Пушкина - «Александр Серегевич с нами». Вдохновение для репертуара школ черпается не только из отечественной и мировой классики, и не только из пьесс или романов. Например, новый петербургский спектакль готовится по стихотворениям китайских поэтов Ли Бо и Ду Фу.

Через творческие практики общения и обсуждение отношения к изучаемому литературному произведению создается художественный рисунок будущего спектакля. Материалами или идеей для спектакля могут послужить ассоциации из общего культурного кода и релевантные личные истории участников. Так на лаборатории, в рамках которой совместно всем коллективом формируется тема спектакля, она может зародиться через откликнувщуюся коллективу упомянутую кем-то песню (как в случае «Ночи Холстомера») или в рассказах о том, что участники больше всего любили в детстве (как в новосибирском спектакле «Unреальность»). При этом, инклюзивный театр очень живой и подвижный в своих пратиках. «Часто [ученики] не выполняют сценический рисунок, который мы выстроили заранее. В один момент, когда актёр театра “Старый дом” не смог прийти на репетицию, а Миша, его партнёр с синдромом Дауна, вдруг начал играть в сцене клоунады за всех, кого нет... Оказалось, что он не просто знает рисунок своей роли: он досконально знает рисунок всех, кто находится в этот момент на сцене. ...Миша, придя к нам заниматься, не разговаривал и сидел в углу, которому папа, бизнесмен на “мерседесе”, говорящий, что это глупость, запрещал ходить в “Инклюзион”, - мы вдруг увидели, чего Миша добился» (Сборник 2020: 54. Зиновьева А., Куратор школы, режиссер, педагог НГТИ).

\section{Что театр значит для людей с инвалидностью? (кейс Новосибирска)}

Инклюзион в Новосибирске начался с проекта - театральной студии Ольги Стволовой «Особенный ТИП» в 2015 г., и только позднее появилось сотрудничество с «Инклюзионом», в 2017 г. К тому моменту у студии уже был опыт создания и постановки 8 спектаклей, представленных в рамках различных городских мероприятий. «Я не ставлю себе задачи лечить людей, которые приходят к нам. Я ставлю задачу создать интересный художественный продукт» (видео «Особенный театр О. Стволовой»). Сама Ольга передвигается на коляске с 9 лет. 


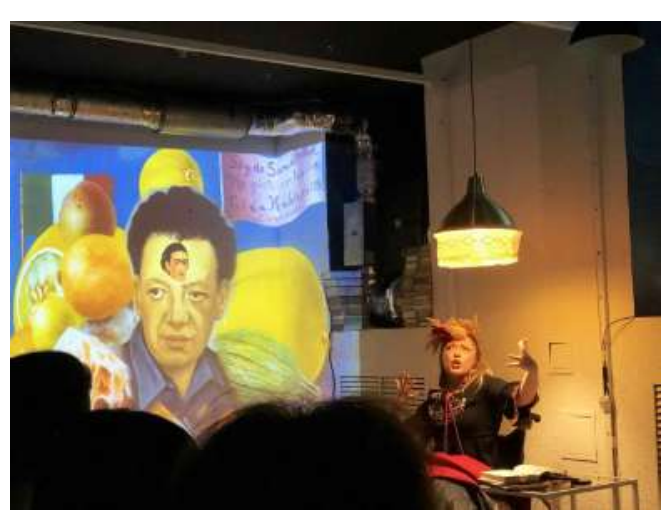

Рис. 3. Спектакль “Несильный”, 2020, Новосибирск (фото: Л.А. Торлопова).

В личных профилях студентов на сайте Инклюзиона прослеживаются те ценностные ориентиры, которые значимы для участников проекта. Это и «новое открытие», где каждую репетицию Берсенев Д. «ждет с нетерпением», и «чувство "близкого плеча" и своя роль в общем результате». Это и «одна большая семья, где всегда тепло и уютно» (Головеев Е.). Это и «увлекательное путешествие, в которые мы вместе отправились!» (Шкурин В.). Это и приятное разнообразное «действо», наполненное свободой: «Чего я только не делаю на занятиях - я никогда столько не гудела, не шелестела, не шипела, не открывалась, не общалась. Это, какое - то освобождение! Легкие наполняются, границы стираются, сознание расширяется» (Колесникова Е.). «Инклюзион - это энергия! ... Там я живая» (Колесникова Е. Видео-презентация “Инклюзион. Школа. Новосибирск”).

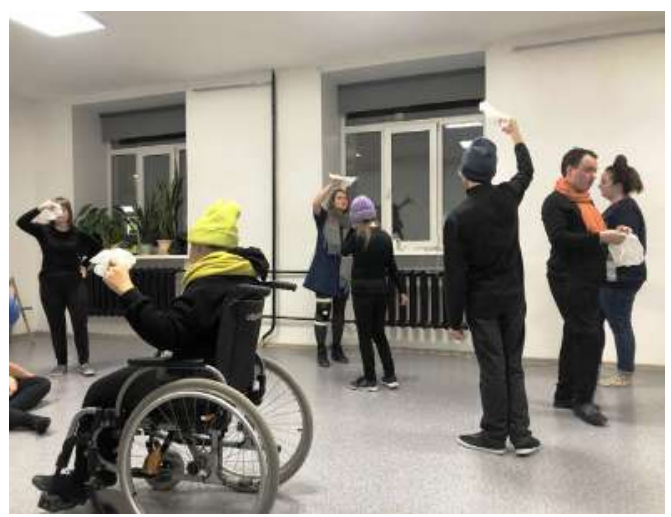

Рис. 4 Открытый урок в школе

Инклюзиона, 2020, Новосибирск (фото: Л.А. Торлоповой).

Благодаря постоянному процессу обучения разным творческим практикам в театральной школе ее ученики приобретают также коммуникативные навыки, приобретают психологическую устойчивость; познают разнообразие мира, как творческого, личностного (через других учеников и профессиональных педагогов, через упражнения и презентацию многочисленных различных творческих этюдов), так и публичного, широко социального (через открытые мероприятия школ, через непосредственно спектакли и взаимодействие со зрителем).

Артисты с инвалидностью ощущают свою «нужность», значимость (что является потребностью любого человека), а также задействованность как в сообществе творческом, так и более широко - в обществе, когда они играют в спектаклях для сторонних, условно здоровых зрителей. В рамках такого открытого и коммуникативно ориентированного проекта участники могут реализовывать свой потенциал не только не только чтобы что-то приобретать (будь то навыки, знания, внимание), но также и отдавать. По словам студента Новосибирской школы, деятельность внутри театральной школы, «...это не была реабилитация, как обычно у нас. Изначально направленность была на спектакль, а не на помощь какую-то. ... Мы о себе рассказываем, о друг друге. Если классический театр он все-таки заставляет идти за автором, то в документальном театре можно что-то изменить. Это заставляет искать живое - в себе» (Видео «Человеческий фактор. Над барьерами»). 


\section{Зачем профессиональным артистам без инвалидности социальный театр?}

В регионах оплата за спектакль является свободной или скромной (200-400 рублей). С учетом того, что обычно аудитория спектакля небольшая (несколько десятков человек, до 40-50), то это не покрывает расходов по тратам театра, является лишь их частичным возмещением. В основном актеры в рамках проекта пока работают как волонтеры, без заработной платы. Каждая школа подает заявки на гранты, помимо поддержки со стороны Фонда «Со-действие», за счет которого и существует проект.

Значимым становится желание сделать видимым: картину, которую люди с нарушением зрения ранее не могли увидеть, а порой - самих незрячих людей (для себя, для мира). Они становятся видимыми «не только потому, что мы выводим их на сцену, но и потому что мы вступаем с ними в личный контакт, которого мы избегаем или лишены в обычной жизни». Для других это про подпитку собственного чувства справедливости. Для третьих - самореализация таланта педагога, когда результаты трансформации восприятия студентов видны уже в течение пары недель. Четвертым именно работа в инклюзивном пространстве позволяет сделать прозрачным, ясным смысл своей профессии: «Когда я пришла в инклюзию, я вдруг увидела смысл своего существования на земле... тут приходят люди, которым с физической точки зрения это нужно” [ответы из зала, педагог по вокалу] (Пархомовская 2019). Профессиональные артисты, приходящие в пространство инклюзивного театра, говорят о тех возможностях вопреки невозможностям, которые они наблюдают в жизни студийцев. «Такое впечатление, что у них возможностей значительно больше, чем у меня, любить жизнь. Это обогащает и дает силы жить» (В. Лемешонок, заслуженный артист РФ, видео “Человеческий фактор”).

$* * *$

Итак, какие же ценности наиболее значимы в рамках существования инклюзивного театра? Волновой «пучок» трех участников трансформации: человек, его/ее инвалидность и театр/искусство делают акцент на свободе. Это «свобода творчества», мысли, жизни, демонстрации себя и своих талантов: «Раньше приходя в театр или на выставку куда-либо, мне казалось, что я не вижу, не могу понять или считать то, что, как мне казалось, все видят [задумку автора]. И меня это тяготило и отталкивало от всех этих заведений. А здесь на занятиях [театральной школы] я могу видеть то, что я вижу; у меня могут быть свои ассоциации на то, что говорит преподаватель, или показывает одногруппник в своем этюде, и здесь это поощряется» (ПМА-1, интервью 3: Софья, ученица с нарушением зрения). Инклюзивный театр вносит в социальное поле разнообразие; показывает возможность свободы быть иным и радости быть принятым в этом. Стирание границ и знакомство с Другим (миром) приводит к интеграции разных миров друг в друга (с инвалидностью и без). Качество жизни зависит от того, чем наполнен человек, его жизнь и тело. Скажем, радостью, счастьем, яркими эмоциями, открытостью миру и желанию идти в контакт или изоляцией, нездоровьем, невозможностью и т.д.

По словам режиссера студии в Казани, «Если ты немой, то ты просто имеешь иной способ выражения, если у человека ДЦП, то это просто иной способ движения и т. д.» (Сборник 2020: 48). Некоторыми авторами театр считается идеальным пространством 
для исследования проблемы «взаимосвязи искусств», «будучи “синтетическим” по самой своей природе» (Бушуева 1991: 4, 7). С учетом описанного подхода, можно предположить, что театр является удачным пространством не только исследования, но и проживания; а также не только искусств, но и взаимосвязи иных различных объектов, размещенных на пересечении разных силовых линий». Такими «объектами» могут выступать человек, инвалидность, отношения между людьми, уровень представления социума об уязвимых группах населения. По словам Августо Боула, театрального директора, драматурга и писателя, автора практического проекта «Театр для угнетенных»: «Нам всем стоит стать частью театра, чтобы узнать, кто мы есть, и чтобы исследовать, кем мы могли бы стать» (Boal 2006: 1). Это и есть трансформационная сила театра, в частности театра - социальной драмы.

Инклюзивный театр - это не панацея. Но это путь, вариант, выбор, живое изменяющееся пространство. Это искусство и причем, это «живое» искусство, которое само идет на контакт, откликается на запрос, готово открываться и меняться вместе с Другим. Тогда жить с присутствием Театра и внутри Театра становится образом жизни. А болезнь или инвалидность можно воспринять как способ совершить парадигмальный сдвиг своего сознания, и обратиться к желаемому - к творчеству, свойственному человеку от природы.

\section{Источники и материалы}

Видео-презентация - Видео-презентация Инклюзион. Школа. Новосибирск. Доступ: https:// vk.com/video166110968_456240587.

ВО3 - Всемирная организация здравоохранения. Доступ: https://www.who.int/mediacentre/ news/releases/2011/disabilities_20110609/ru/ (Дата обращения: 11.06.20).

Морозова 13 - Морозова Т. Выход в люди. Что может сделать полноценной жизнь инвалида в Новосибирске. Доступ: /https://sib.fm/interviews/2013/04/15/vykhod-v-ljudi от 15.04.2013 (дата обращения: 19.01.20).

Инклюзион/ О центре - Инклюзион / О центре. Доступ: http://inclusioncenter.ru/o-centre/.

Пархомова 2018 - Видео «Раз, два, фест». Рассказ Н. Пархомовской о фестивалях социального театра. 2018. Доступ: https:/www.youtube.com/watch?v=ciP8o4d5O5o (Дата обращения: 14.07.20).

ПМА 1 - Расшифровка интервью со “студийцами” в Новосибирске и записи со включенного наблюдения.

Спектакль - Видео спектакля «Unреальность». Инклюзион. Новосибирск. Доступ: https:// www.youtube.com/watch?v=0rQ0kBIFdwA (Дата обращения: 23.05.20).

О театре - О театре // “Театр Простодушных”. Доступ: театрпростодушных.pф/?page_id=2 (дата обращения: 08.08.20).

Человеческий фактор - Видеозапись программы «Человеческий фактор. Над барьерами» // ТК Культура. Доступ: https://tvkultura.ru/video/show/brand_id/63397/episode_id/2236390/ video_id/2265456/ (Дата обращения: 24.03.20).

Что такое - Что такое “социальный театр” и зачем ему нужен собственный фестиваль? // Инклюзион. Доступ: http://inclusioncenter.ru/znanija-soobshhestva/chto-takoe-socialnyj-teatr/.

\section{Научная литература}

Афонин А. Б. «Особый театр» как жизненный путь. М.: ИД Городец, 2018. 160 с.

Бушуева С. К., Овэс Л. С., Таршис Н. А. (под ред.). Взаимосвязи: Театр в контексте культуры: Сборник научных трудов, 1991. 154 с. 
Дунаева А., Пархомовская Н. (отв. ред.). Социальный театр в России: Сборник материалов по итогам I Форума-фестиваля социального театра «Особый взгляд». М., 2020. 144 с.

Курленкова А.С., Носенко-Штейн Е.Э. (отв. ред.). Обратная сторона Луны, или что мы не знаем об инвалидности: теория, репрезентации, практики: сб. статей. М.: Изд-во МБА, 2018. $420 \mathrm{c}$.

Маркина В. М. «Театр Простодушных»: потенциал социальной инклюзии и дестигматизации людей с синдромом Дауна // Социология и общество: глобальные вызовы и региональное развитие: Материалы IV Очередного Всероссийского социологического конгресса. М.: POC, 2012. С. 7965-7974.

Хейзинга Й. Ноmo Ludens. Статьи по истории культуры. / Пер. с гол. Д. В. Сильвестрова. М.: Прогресс -Традиция, 1997. 416 с.

Boal A. The Aesthetics of the Oppressed. Translated by Adrian Jackson. London \& New York: Taylor \& Francis e-Library, 2006. 136 p.

Jimenez-Aceituno A., Medland L., and others. Social theatre as a tool for environmental learning processes: a case study from Madrid, Spain // Across the Spectrum. Resources for Environmental Educators / eds. Martha C. Monroe, Marianne E. Krasny. University of Florida, Cornell University, the North American Association for Environmental Education, and the U.S. Environmental Protection Agency. 2016. P. 281-297.

Torlopova, Lubov A.*

\section{Theatre as a "Way of Life" for Persons with Disabilities: Anthropological Observations}

DOI: $10.33876 / 2311-0546 / 2021-53-1 / 50-60$

Based on a pilot study, the article traces the links between disability and art: what path does a person with a disability take on the way to theatrical creativity? The answer to this question is built through an attempt to consider the life of a person with a disability as a kind of social drama, and to see what transformations occur when real lives interact with real theatre. The usual context of a theatre is shifting from the format of fictional characters and their stories, packed in the framework of the imaginary world of one author, towards characters who co-create an artistic project with realistic details of their individual life narratives. This is made possible by the phenomenon of social theater. Social and inclusive theater contains, in addition to the aesthetic component, a horizontal hierarchy, where each participant is a creator on an equal footing, with his/her own areas of responsibility. The image of an inclusive theater is revealed in the article on the concrete example of the big Russian project "Incluzion", which works in seven cities of Russia. The Novosibirsk case of a theater network demonstrates which values are positioned by artists with disabilities as those that make a person's life "fulfilled", despite "limited opportunities".

Keywords: disability studies, disability, social theatre, inclusion, inclusive art, persons with disabilities, inclusive theatre

For Citation: Torlopova, L.A. 2021. Theatre as a "Way of Life" for Persons with Disabilities: Anthropological Observations. Herald of Anthropology (Vestnik Antropologii) 1 (53): 50-60.

*Torlopova, Lubov A. - Researcher, Tomsk State University (Tomsk, Russian Federation). E-mail: lyubovtorlopova@gmail.com. Orcid.org/0000-0003-2809-9965

The research was supported by the Russian Foundation for Basic Research (RFFI, project No. 20-09-0063) 


\section{References}

Afonin, A.B. 2018. "Osobyi teatr" kak zhiznennyi put ["Especial theatre" as a life way]. Moscow: ID Gorodets.

Boal, A. 2006. The Aesthetics of the Oppressed. Translated by Adrian Jackson. London \& New York: Taylor \& Francis e-Library.

Bushueva, S.K., L.S. Oves and N.A. Tarshis, eds. 1991. Vzaimosviazi: Teatr v kontekste kul'tury: Sbornik nauchnykh trudov [Relationships: Theater in the Context of Culture. Collection of Scientific Papers].

Dunaeva, A., and N. Parkhomovskaia, eds. 2020. Sotsial'nyi teatr v Rossii: Sbornik materialov po itogam I Foruma-festivalia sotsial'nogo teatra "Osobyi vzgliad" [Social theater in Russia: The Collection of materials on the results of the 1st Forum-Festival of Social Theater "Special Look"]. Moscow.

Huizinga, J. 1997. Homo Ludens. Stat'i po istorii kul'tury [Homo Ludens. A study of the playelement in culture]. Translation from Dutch D.V. Sil'vestrova. Moscow: Progress-Traditsiia.

Jimenez-Aceituno, A., L. Medland and others. 2016. Social theatre as a tool for environmental learning processes: a case study from Madrid, Spain. In Across the Spectrum. Resources for Environmental Educators, ed. by Martha C. Monroe, Marianne E. Krasny, 281-297.

Kurlenkova, A.S., and E.E. Nosenko-Shtein, eds. 2018. Obratnaia storona Luny, ili chto my ne znaem ob invalidnosti: teoriia, reprezentatsii, praktiki: sb. Statei. [The Far Side of the Moon, or What We Don't Know About Disability: Theory, Representations, Practices] Moscow: Izdatel'stvo MBA.

Markina, V.M. 2012. “Teatr Prostodushnykh”: potentsial sotsial'noi inkliuzii i destigmatizatsii liudei s sindromom Dauna. ["Theater of the Innocent": The Potential of Social Inclusion and Destigmatization of People with Down Syndrome] In Sotsiologiia i obshchestvo: global'nye vyzovy i regional'noe razvitie: Materialy IV Ocherednogo Vserossiiskogo sotsiologicheskogo kongressa. Moscow: ROS. 7965-7974. 